\title{
Qual a importância de uma época? Anacronismo e história
}

\author{
André Fabiano Voigt
}

Resumo: O presente artigo procura - a partir do problema colocado no dossiê "Presença dos anos 1980: esperanças, nostalgias e historiografia" - realizar uma análise retroativa a autores como Immanuel Kant, Georg W. F. Hegel e Karl Marx e estabelecer as divergências e convergências entre estes autores em torno de um fio condutor: qual é a relação que o ser humano tem com o tempo, o espaço e a prática da liberdade? Qual a importância, portanto, de uma "época" para a análise histórica? Percebe-se que, apesar de Hegel e Marx seguirem elementos importantes do pensamento kantiano, ambos convergem em um princípio que se distingue da análise de Kant: a noção de que alguns grupos ou indivíduos teriam uma visão/compreensão (Einsicht) melhor da situação de todos. Neste sentido, entendemos que a sequência entre a crítica kantiana e o pensamento contemporâneo está principalmente na obra de autores que pensaram a crítica do filósofo de Königsberg como "atitude crítica" diante do pressuposto da autoridade. Entre esses autores, encontram-se Michel Foucault e Jacques Rancière, que defendem a característica eminentemente anacrônica do trabalho do historiador, sem a pressuposição da superioridade de um indivíduo ou grupo sobre os demais.

Palavras-chave: Época. Historicismo. Anacronismo. Michel Foucault. Jacques Rancière.

"Doutor em História e professor associado do Instituto de História e do Programa de Pós-Graduação em História da Universidade Federal de Uberlândia - UFU. E-mail: voigtandre@hotmail.com 
Falar sobre épocas como a "década de 80 " é sempre algo muito desafiador. Em um momento tão conturbado como o atual, não pretendemos repetir as expressões empregadas por Hannah Arendt que são tão recorrentemente utilizadas nos dias de hoje, como "tempos sombrios", ou a "banalidade do mal" - expressões que correm o risco de colocar, de princípio, um certo tom de superioridade escandalizada em relação à suposta ignorância em que vivemos.

Pretendemos fazer, neste artigo, uma breve reflexão - bastante inacabada e incipiente sobre o tema que caracteriza este dossiê: "presença dos anos 80". O que é a importância de ressaltar uma época para a atualidade? O que teria os "anos 80 ” em especial em relação às outras? Teria sido a abertura em relação ao regime militar? O movimento Diretas Já? O Plano Cruzado, que fez desaparecer produtos como o leite dos refrigeradores dos supermercados? A quantidade de desenhos animados e de programas infantis, como o Xou da Xuxa, Angélica, Bozo ou Sérgio Mallandro? O fato de que a seleção brasileira de futebol não ganhou nenhuma Copa do Mundo naquela década? Teria sido talvez a morte misteriosa de Tancredo Neves? O que torna, afinal, uma "época" tão importante a ponto de ser tão lembrada hoje, trinta anos depois?

Esta pergunta não é algo meramente ingênuo, que deve ser pressuposto como dado historicamente, sem que se façam outras perguntas de fundo: quais são os mecanismos que tornam possível ao historiador a demonstração de que uma "época" possui uma característica determinada? Além disso, o que permite afirmar que sua importância reside em uma "essência" a qual conhecemos apenas hoje e, ademais, cuja conscientização desta essência resultará em um processo histórico de emancipação de nosso país das garras do poder mesquinho ao qual nos encontramos hoje? Estas perguntas, as quais tacitamente são ignoradas em nossos "tempos sombrios", curiosamente encontram respostas em um conjunto de elementos que os historiadores costumam chamar, de modo geral, de teoria e método. Estariam dados de antemão os principais elementos que definem o que são a teoria e o método em nosso ofício? Este é um ponto que vale a pena nos demorarmos um pouco.

Este assunto está, acreditamos, inserido em um debate que já dura aproximadamente duzentos anos e envolve, principalmente, 
dois filósofos que pensaram o significado das noções de tempo e espaço para o conhecimento humano e, por sua vez, para a história: Immanuel Kant e Georg W. F. Hegel - cujas consequências de seus pensamentos foi significativamente trazida para a obra de Karl Marx e outros pensadores da atualidade. Iniciaremos nossa investigação com Kant.

O filósofo de Königsberg, em sua primeira obra crítica, a Crítica da Razão Pura (2010) - sobretudo na parte denominada Estética transcendental - trata dos conceitos de tempo e espaço como "formas puras da intuição sensível”, que tornam possível fazer a síntese do diverso dos fenômenos na consciência por meio de conceitos do entendimento, formando o que o autor chama de "unidade sintética originária da apercepção" (KANT, 2010, p. 129137). Neste sentido, seria possível colocar no sujeito observador e em sua consciência no tempo a síntese do diverso dos fenômenos empíricos. Contudo, é importante salientar que, no interior da crítica kantiana, os elementos para o conhecimento empírico de determinado objeto não se encontram nem apenas no objeto (empirismo), nem somente no sujeito (idealismo). É no concurso indissociável entre sujeito e objeto que se encontram as bases do conhecimento empírico. O tempo e o espaço, destarte, não são dados puramente objetivos, mas também se situam no uso das faculdades de quem observa, evitando, assim, o dogmatismo que atribui o conhecimento da realidade somente aos objetos. Portanto, no interior do pensamento kantiano, tempo e espaço são noções tomadas a priori para o conhecimento empírico da natureza.

Avançando um pouco no raciocínio kantiano, já existe no "Apêndice à dialética transcendental" da Crítica da Razão Pura (2010) uma saída para o conhecimento sistemático da natureza que, por sua vez, dá elementos para a constituição de uma filosofia crítica da história. ${ }^{1} \mathrm{O}$ filósofo alemão entende que não há como conhecer a natureza em sua totalidade fenomênica, pois não há uma generalidade dada a priori, a partir da qual se possam subsumir as diversas particularidades com o uso apodítico da razão. Deste modo, Kant compreende que se pode utilizar o que chama de "uso hipotético da razão", o que significa "encontrar um princípio para o diverso e para uso particular do entendimento e desse modo guiar 
esse uso e colocá-lo em conexão também com os casos que não são dados” (KANT, 2010, p. 536). Portanto, Kant defende que, no conhecimento do diverso em que não há uma generalidade dada de princípio, precisamos encontrar princípios regulativos da razão para orientar nosso pensamento, de modo a dar unidade sistemática aos conhecimentos diversos do entendimento. Ora, esse é o problema fundamental da história, uma vez que, em meio à diversidade dos fatos, temos somente suas particularidades dadas, e não temos, a princípio, nenhuma regra geral que submeta as particularidades.

Este tema é tratado novamente na sua terceira crítica, intitulada Crítica da Faculdade do Juízo (2008), em que o autor volta ao tema do conhecimento da natureza, desta vez como um problema de juízos teleológicos - ou seja, orientados em conformidade a fins. Bruno Nadai, em sua tese Progresso e moral na filosofia da história de Kant (2011), bem aponta que há uma diferença fundamental entre o "Apêndice" da primeira crítica e a terceira crítica:

Deste ponto de vista, a diferença fundamental entre o "Apêndice" e a terceira crítica reside em que, nesta última, o conceito de conformidade a fins não está mais associado ao "uso hipotético da razão", mas é elevado ao status de "princípio transcendental próprio à faculdade do juízo". A partir daí, torna-se ainda mais clara a clivagem entre o conhecimento objetivo da natureza e a teleologia da natureza. Com isso, fica também mais evidente que a filosofia da história kantiana não tem a pretensão de ser um conhecimento objetivo sobre a história, mas (no caso de sua justificação teórica) responde apenas a uma necessidade racional de exposição sistemática do agregado dos fenômenos das ações humanas. (NADAI, 2011, p. 61, grifo nosso).

Ainda na terceira crítica, Kant expõe, na seção 79, que a teleologia não está relacionada à faculdade de juízo determinante em que os universais estão dados e submetem as particularidades a regras e leis gerais -, mas sim, à faculdade de juízo reflexiva na consideração da natureza - em que somente as particularidades estão dadas e uma generalidade precisa ser alcançada a partir da 
sistematização das mesmas sob um princípio regulativo (KANT, 2008, p. 257-258). Seguindo a linha de raciocínio kantiana, o autor entende que a teleologia não está ligada à doutrina, mas sim à crítica, na medida em que "possui uma influência negativa sobre a forma de proceder da ciência natural teórica", bem como sobre "a relação que esta pode ter na metafísica em relação à teologia, enquanto propedêutica da mesma” (KANT, 2008, p. 258).

Ora, a empreitada crítica - que não se pode confundir com um "ser-no-mundo" aos moldes do pensamento de Heidegger em Ser e Tempo (HEIDEGGER, 2013, p. 158-246, §23-§38) - é muito mais, em concordância com Michel Foucault, uma atitude de investigar as "relações entre poder, verdade e sujeito" (FOUCAULT, 1990, p. 46), que não toma nenhum evento, tema ou questão a partir da "encarnação de uma essência", mas sim, é a investigação das condições de possibilidade de aceitação de um sistema, tomado em seu "campo de imanência das singularidades puras" (FOUCAULT, 1990, p. 50). Desta feita, a atitude crítica não é a tomada de princípio da independência do uso da razão para resolver os problemas da humanidade com raciocínios definitivos e com a busca de verdades permanentes: é investigar, em um nível mais profundo, que a aceitabilidade de um sistema é indissociável do reconhecimento de sua "arbitrariedade em termos de conhecimento, sua violência em termos de poder" (FOUCAULT, 1990, p. 50), desviando-se bastante de aspectos fundamentais do pensamento heideggeriano. Heidegger, principalmente em Ser e Tempo, pretende centralizar o conceito de "ser-no-mundo" a partir de uma "virada ontológica", em que, ao caracterizar ontologicamente a "mundanidade do mundo", aposta na capacidade do ser humano em compreender - sobretudo por meio do poder da linguagem - como instrumento para interpretar e desvelar a verdade do ser em seu Dasein. ${ }^{2}$

De todo modo, a empresa crítica kantiana revela-nos elementos importantes para pensar a história e demonstrar qual a forma de juízo que se emprega para pensar historicamente. Como aponta Foucault, a atitude crítica se sustenta no campo de imanência das "singularidades puras". Em outras palavras, para conhecer a história em sua unidade sistemática, deve-se partir do uso de juízos reflexivos, de forma a buscar as generalidades por meio de princípios 
regulativos - e não de juízos determinantes, em que os universais estão dados. Curiosamente, esta é a chave tanto para a filosofia da história, debatida no século XIX, quanto para verificar uma importante ruptura no pensamento histórico da modernidade. A unidade sistemática da história - baseada em juízos teleológicos - e o juízo de gosto - fundamentada a partir de juízos estéticos - possuem uma mesma base: o uso de juízos reflexivos, partindo da individualidade/ singularidade da experiência, tanto estética quanto histórica. ${ }^{3}$

Alfred Baeumler, em seu livro Das Irrationalitätsproblem in der Ästhetik und Logik des 18. Jahrhunderts bis zur Kritik der Urteilskraft [O problema da irracionalidade na estética e na lógica do século XVIII, tradução nossa] afirma, de modo sucinto e instigante, que:

\begin{abstract}
A estética é a precursora da historiografia moderna. Ao ensinar a compreender a individualidade, ela revelou ao mesmo tempo o mundo individual da história e o problema de seu conhecimento. O século XVIII é o berço do significado histórico porque é o berço da estética. (BAEUMLER, 1981, p. 15, tradução nossa).
\end{abstract}

Esta afirmação polêmica de Baeumler, feita ainda na década de 1920, é a chave para a elevação do conhecimento histórico a uma categoria superior durante o século XIX: para deixar de ser um mero conhecimento do fato nu, ela se orienta conforme princípios postos a priori como forma de unificar sistematicamente um agregado de fenômenos das ações humanas. Ora, a colocação de princípios regulativos a priori só é possível quando, obrigatoriamente, nos colocamos em diversas temporalidades em coexistência. Não seria esse justamente o problema do anacronismo como base para a história e fundamento das condições últimas da historicidade?

Deste modo, colocar-se em temporalidades diferentes pressupõe outra atitude diante da tradição e da autoridade, sobretudo aquelas relacionadas à retórica e eloquência da Antiguidade clássica, que partiam de universais dados para submeter os eventos particulares da história humana. Como bem aponta Foucault, "há alguma coisa na crítica que se aparenta à virtude” (FOUCAULT, 
1990, p. 36). Assim, é na convergência entre a atitude crítica e a prática da virtude que se situa o exercício da liberdade.

Kant, principalmente em sua Metafísica dos Costumes (2013), separa a doutrina do direito da doutrina da virtude/ética. Neste último livro, Kant propõe que exista um limite na coerção externa realizada pelo direito das gentes e pelos costumes enraizados pela educação. O exercício da virtude ética - que é a prática refletida do uso da liberdade do arbítrio - não pode ser feito a partir de uma coerção externa, pois alguém pode ser coagido por outrem a ações que como meio, são dirigidas a um fim, mas, por outro lado, ninguém pode ser coagido a ter um fim: apenas posso propor-me algo como um fim (KANT, 2013, p. 191). Desta maneira, o exercício da liberdade não necessariamente coincide com os limites da tradição imposta pelo direito e pelos costumes, da mesma forma que não pode ser imposto por alguém conforme fundamentos empíricos das máximas do dever (KANT, 2013, p. 192). Neste sentido, Kant desvencilha-se parcialmente do peso da tradição da Antiguidade e da metafísica das gerações anteriores, centrando seu projeto crítico em um "olhar para o futuro", mediante fins postos a priori. Esta ideia está, conforme estudiosos de Kant (NADAI, 2011) no conjunto de toda a obra crítica kantiana, figurando também como um dos elementos relevantes do opúsculo Ideia de uma história universal de um ponto de vista cosmopolita (2011), que teria inspirado uma noção de história bastante visível em dois filósofos que lhe sucederam, sobretudo em Hegel e Marx - embora haja alguns pontos de divergência que precisem ser melhor elucidados a seguir.

Dando continuidade à nossa investigação, Hegel retoma o pensamento kantiano e realiza uma mudança de foco para os limites kantianos do conhecimento empírico. No segundo volume de sua Enciclopédia das Ciências Filosóficas (1847), Hegel entende inicialmente que as noções de tempo e de espaço são, conforme Kant, formas puras da sensibilidade ou do intuir. No entanto, Hegel muda severamente os rumos postos pelo kantismo neste aspecto. Hegel coloca o tempo como a própria inscrição do devir. Em outros termos: não é no tempo em que tudo surge ou perece, mas o próprio tempo é esse devir, o surgir e o perecer (HEGEL, 1847, p. 53-54, § 
258). Continuando sua explicação sobre o tempo, Hegel entende que o real, considerando sua exterioridade e finitude, está no tempo e é distinto do tempo - embora lhe seja essencialmente idêntico -, mas o conceito - devido ao fato de conter em si mesmo sua negatividade como essência universal sua - não está no tempo e nem é temporal. Desta maneira, Hegel conclui que apenas o natural está submetido ao tempo, por ser finito, enquanto que o verdadeiro, pelo contrário, é eterno (HEGEL, 1847, p. 54, § 258). Ao fazer coincidir o verdadeiro com a eternidade, o autor entende que a eternidade não é algo que está fora do tempo ou seria mera abstração, mas sim, seria o próprio tempo em sua essência. Ora, desta maneira, a essência do tempo é a verdade, que é eterna, em si e para si.

O conceito de espaço torna-se, para Hegel, algo distinto daquilo que teria apontado Kant - uma forma da intuição sensível. O espaço seria, em sua visão da definição kantiana, uma mera abstração da exterioridade imediata. $\mathrm{O}$ espaço, para Hegel, seria então a primeira determinação da natureza, em sua abstrata universalidade de seu ser-fora-de-si, sem possuir nenhuma diferença determinada ou mediada, formando um grande contínuo indiferenciado (HEGEL, 1847, p. 44-45, § 254). Por isso, o espaço é uma quantidade pura, que passando pelo tempo, constitui uma primeira determinação mútua que é o lugar (HEGEL, 1847, p. 62, § 260-261). Desta forma, o lugar (Ort) é simultaneamente a identidade entre tempo e espaço e sua contradição mútua, por sua singularidade espacial e seu momento no tempo. Como estas duas noções são aplicadas à história no pensamento hegeliano?

As noções de tempo e de espaço servem para a aplicação de um princípio do desenvolvimento (das Princip der Entwickelung) para a história. Vejamos como isso se aplica nas lições sobre a filosofia da história, realizadas por Hegel e publicadas após sua morte. Inicialmente, o princípio interior (Espírito) desenvolve suas potencialidades pressupostas na história do mundo (espaço e tempo), contra a ação externa dos acidentes (HEGEL, 1848, p. 67-68). Assim, há na história mundial grandes períodos que se extinguiram, em que foi aniquilado todo o seu "ganho de cultura" (Gewinn der Bildung), não aparentando uma continuidade do seu desenvolvimento; por outro lado, há contínuos desenvolvimentos (fortbestehende Entwickelungen), 
observados em "estruturas e sistemas de cultura" (Gebäude und Systeme von Bildung) em seus elementos peculiares (HEGEL, 1848, p. 68-69). Portanto, Hegel conclui que a história do mundo apresenta o progresso gradual (Stufengang) do desenvolvimento do princípio, cujo conteúdo é a consciência da liberdade (HEGEL, 1848, p. 70). Nesta caminhada em etapas, o princípio do desenvolvimento consiste em atestar como desde os primeiros vestígios do espírito já se contêm virtualmente toda a história mundial. Hegel faz questão de colocar esse desenvolvimento em etapas. Em primeiro lugar, os orientais, que não sabem que o espírito é livre, mas apenas um é livre - talvez por mero "acidente da natureza" (Naturzufall), como déspota. Logo após, os gregos foram os primeiros a ter a consciência da liberdade, mas eles - assim como os romanos - apenas sabiam que alguns eram livres, mas não a humanidade; por isso, tinham a escravidão. Apenas os povos germânicos, por meio da cristandade, se conscientizaram que a humanidade é livre e que a liberdade do espírito é a essência de sua natureza - conseguida inicialmente pela religião, mas foi introduzida no mundo leigo por um "longo e difícil trabalho da civilização" (schwere lange Arbeit der Bildung) (HEGEL, 1848, p. 23). Na descrição hegeliana das etapas da caminhada histórica da humanidade rumo à consciência da liberdade, nota-se a importância crucial de alguns povos e de algumas épocas para a história da humanidade.

Mas, qual o mecanismo que levaria à compreensão total das etapas e sua superação rumo à consciência da liberdade? As ações dos indivíduos na história. Além disso, qual seria o critério usado para identificar, na história mundial, as ações individuais que representariam o que é a caminhada do espírito rumo à sua realização no mundo e aquelas que não a representariam? Hegel responde que o critério reside na ação dos "indivíduos históricos" (welthistorischen Individuen), "cujos objetivos particulares contêm o substancial, o qual é a vontade do espírito do mundo" (deren eigene particulare Zwecke das Substancielle enthalten, welches Wille des Weltgeistes ist) (HEGEL, 1848, p. 37-38). Em contraposição às ações dos indivíduos movidos por "interesses particulares" (particulare Interesse), cujos "afetos anseiam por satisfação" (Leidenschaft, welche Befriedigung verlangt), os indivíduos históricos - chamados 
por Hegel de "heróis" - têm a visão/compreensão (Einsicht) do que é necessário e em que momento, incorporando a "razão, a justiça, a liberdade" (die Vernunft, das Recht, die Freiheit) (HEGEL, 1848, p. 44), ainda que "não tenham consciência da Ideia como tal" (solche Individuen hatten in diesen ihren Zwecken nicht das Bewusstsein der Idee überhaupt) (HEGEL, 1848, p. 38).

Assim, poderíamos entender, segundo o autor, que uma "época" só possuiria importância histórica se nela pudesse ser vista - ainda que acidentalmente - o germe da consciência da liberdade em ações de "indivíduos históricos", cujos interesses particulares são a incorporação da razão, da justiça e da liberdade em seu próprio tempo e lugar. Por isso, podemos concluir que, no próprio pensamento hegeliano, o exercício da liberdade depende de um processo histórico empírico e um "longo e difícil trabalho da civilização" - tomando um rumo bem diferente da separação kantiana entre a doutrina do direito e a doutrina da virtude - centralizando a mudança entre uma época e outra na ação de indivíduos históricos que incorporam a "verdade do seu tempo e de seu mundo" (HEGEL, 1848, p. 38). Complementando a caminhada em etapas para a realização do espírito na história mundial, Hegel aponta, ao contrário de Kant, que as instâncias do direito e do dever apenas encontrariam sua convergência na constituição do Estado como realidade moral submetida a uma constituição, que apresentasse a síntese entre a substancialidade do dever e os interesses particulares, conforme sua obra Princípios da Filosofia do Direito (HEGEL, 1997, p. 226-227). É neste ponto que se inicia as divergências entre Hegel e um de seus principais críticos: Karl Marx. Em sua Crítica da filosofia do direito de Hegel, Marx (2010) empreende um esforço para estabelecer uma crítica a aspectos do pensamento hegeliano, sobretudo no que diz respeito à ideia que a constituição do Estado seria a realização das esferas do direito e do dever, tornando possível o exercício da liberdade. Marx, na introdução de seu livro, entende que esta ideia posta por Hegel seria de difícil aplicação na Alemanha, na medida em que esta não teria galgado "os degraus intermediários da emancipação política no mesmo tempo que as nações modernas", pois, ainda que os tenha superado "teoricamente" - por meio da religião e da "atividade abstrata do pensamento" - ainda não 
teria alcançado "praticamente" - por meio das "lutas reais desse desenvolvimento" (MARX, 2010, p. 152-153). Por isso, entende que a Alemanha não quer fazer a revolução radical, a "emancipação humana universal" - mas somente a revolução parcial, meramente política. Como seria possível, todavia, fazer uma revolução política? Marx responde afirmando que ela é possível apenas quando "uma parte da sociedade civil se emancipa e alcança o domínio universal", quando uma determinada classe, "a partir da sua situação particular, realiza a emancipação universal da sociedade" (MARX, 2010, p. 154). Ora, esta classe não poderia ser, na visão de Marx, a burguesia, mantida em um Estado que garantisse a propriedade privada. No pensamento de Marx, a revolução humana - e não apenas a revolução política - só poderia ser feita por uma classe que "não seja uma classe", de um "estamento que seja a dissolução de todos os estamentos": o proletariado (MARX, 2010, p. 156). Ao fim da introdução do mesmo livro, Marx defende que a "cabeça dessa emancipação é a filosofia, o proletariado é seu coração" (MARX, 2010, p. 157). Qual a importância desta frase de Marx para a operacionalização revolucionária? Porque, de certa forma, ele mesmo sustenta a ideia, exposta textualmente no prefácio de seu livro Contribuição à Crítica da Economia Política, que:

Do mesmo modo que não se julga o indivíduo pela ideia de que de si mesmo faz, tampouco se pode julgar uma tal época de transformações pela consciência que ela tem de si mesma. É preciso, ao contrário, explicar essa consciência pelas contradições da vida material, pelo conflito que existe entre as forças produtivas sociais e as relações de produção. Uma sociedade jamais desaparece antes que estejam desenvolvidas todas as forças produtivas que possa conter, e as relações de produção novas e superiores não tomam jamais seu lugar antes que as condições materiais de existência dessas relações tenham sido incubadas no próprio seio da velha sociedade. (MARX, 2008, p. 48).

Para que uma época seja conhecida em sua importância histórica, não basta que ela tenha os elementos da autoconsciência do 
espírito expostos em sua realidade social: a consciência da importância de uma época se dá pela explicação das contradições da vida material, entre forças produtivas e relações de produção. Daí surge a pergunta: o proletariado teria, a princípio, condições para saber de sua importância para o momento histórico da revolução humana? Talvez não. Por isso, no início da segunda parte no Manifesto do Partido Comunista de 1848, Marx e Engels afirmam a vantagem do partido comunista em ter uma "visão [Einsicht] clara das condições, da marcha e dos resultados gerais do movimento proletário" (MARX; ENGELS, 2001, p. 46-47). Destarte, os comunistas

Não estabelecem princípios particulares, segundo os quais pretendem moldar o movimento proletário [...] As concepções teóricas dos comunistas não repousam, de forma alguma, em ideias, em princípios inventados ou descobertos por este ou aquele reformador do mundo. São apenas a expressão geral das relações efetivas de uma luta de classes que existe, de um movimento histórico que se processa diante de nossos olhos. (MARX; ENGELS, 2001, p. 46-47).

Ora, aqui percebemos textualmente que, apesar de Marx mudar o critério pelo qual se compreende uma época e sua importância rumo à emancipação humana (não a partir da autoconsciência da liberdade, mas da explicação das contradições da vida material), assim como também muda a característica do agente de mudança histórica do indivíduo (herói) para um grupo específico (proletariado), mantém - sobretudo no Manifesto de 1848 - a ideia que é necessário haver um grupo (os comunistas), cuja visão/compreensão (Einsicht) seria melhor e mais clara para operacionalizar a mudança de uma etapa para outra. O critério empregado por Marx e Engels é, por sua vez, a pura e simples pressuposição que este grupo (os comunistas) não estaria conduzindo o proletariado por meio de "princípios particulares" (besonderen Prinzipien), mas sim, a partir da ideia que seus interesses são a "expressão geral das relações efetivas de uma luta de classes". Neste momento, surge uma indagação de difícil resposta: até que ponto Marx, em sua crítica a Hegel, não mantém aspectos cruciais do pensamento hegeliano, sobretudo na necessidade 
de haver agentes históricos catalisadores da mudança entre épocas, justamente por ter uma "visão/compreensão" (Einsicht) superior a respeito de seu tempo e de seu mundo - de modo a garantir um plano geral da história da humanidade rumo à sua emancipação?

E a partir do debate estabelecido entre Hegel e Marx que se coloca um problema que marcará boa parte das análises históricas, trazendo reflexos para os dias atuais: até que ponto podemos pressupor que há indivíduos ou grupos com uma visão (Einsicht) privilegiada de seu próprio tempo e lugar, cujos interesses nunca são particulares, mas sempre coletivos e até universais? Esta questão, a nosso ver, passa pela problematização do papel da temporalidade na história e da maneira como a articulamos para chegar a nossas conclusões. Apenas em meados da década de 1960 - a partir das obras de autores como Michel Foucault e, posteriormente, Jacques Rancière - alguns importantes aspectos do kantismo são retomados de um modo diferente em relação ao debate hegeliano-marxista.

A despeito do opúsculo kantiano sobre a ideia de história com um propósito cosmopolita, Foucault retoma elementos do kantismo para afirmar, em As palavras e as coisas (1966), um problema fundamental em nossa épistémè moderna: a quebra de um plano contínuo do tempo e a descoberta das diversas historicidades que caminham em planos espaço-temporais distintos que se encontram fragmentados caracterizando, na visão do autor, que "o homem não é, ele próprio, histórico" (FOUCAULT, 1999, p. 509-511). O homem está submetido à superposição de tempos diferentes e, embora o historicismo tivesse como objetivo justificar relações concretas entre totalidades limitadas - talvez entre idades, épocas e contextos específicos, por meio de uma metodologia da compreensão viva, da comunicação inter-humana e da hermenêutica -, estas só são possíveis em sua positividade a partir da finitude que as delimita e as distingue (FOUCAULT, 1999, p. 516-517). Ora, se a lei do tempo é o limite externo das ciências humanas, a História "mostra que tudo o que é pensado o será ainda por um pensamento que ainda não veio à luz" (FOUCAULT, 1999, p. 515), sempre remetendo a compreensão dos mecanismos inconscientes que regem nossas vidas a uma tomada de consciência que ocorrerá em um futuro sempre prometido. 
Talvez por isso, todas as formas de querer resgatar uma temporalidade de base para a história e relacionar todas as outras temporalidades àquela de base podem ser vistas, a partir da reflexão de Foucault, como uma última tentativa da história em se colocar como um saber que ainda quer reconciliar o homem com sua duplicidade empírico-transcendental em um fim específico, resgatando uma teleologia da história que coincide com esta tomada de consciência nunca alcançada pelas "consciências ingênuas", mas que pode ser conseguida por aqueles que podem conduzir as massas para a "grande conscientização", reproduzindo a mesma dinâmica dos mecanismos que regem a diferença entre dominantes e dominados. Desta maneira, é possível concluir que o estudo da história está delimitado pela superposição de temporalidades coexistentes que não se encaixam de maneira estável, caracterizando uma inevitável descontinuidade temporal não apenas como sua condição ontológica, mas também como condição epistemológica sine qua non para a interpretação histórica.

Foucault também retoma aspectos relevantes do kantismo para, em textos como Qu'est-ce que la critique? Critique et Aufklärung (O que é a crítica? Crítica e Aufklärung) (FOUCAULT, 1990), afirmar que a atitude crítica não significa um arrogar a si e a seu próprio grupo uma visão melhor do que é coletivo em seu próprio tempo/ espaço: é, em rigor, o problema em face da autoridade. Esta atitude de "não ser governado" sob certas circunstâncias não é pretexto para, simplesmente, cortar a cabeça dos reis e fazer a revolução total conforme as próprias convicções, mas sim, para expor os perigos de uma certeza profunda que, não devidamente questionada em seus limites, pode levar a problemas de difícil solução:

[...] à força de celebrar que nossa organização social ou econômica carecia de racionalidade, nós nos encontramos frente eu não sei se demais ou insuficiente razão, em todo caso seguramente frente a poder demais; à força de ouvir cantar as promessas da revolução, eu não sei aí onde ela se produziu ela é boa ou má, mas nós nos encontramos frente à inércia de um poder que indefinidamente se mantém; e 
à força de ouvir cantar a oposição entre as ideologias da violência e a verdadeira teoria científica da sociedade, do proletariado e da história, nós nos encontramos com duas formas de poder que se assemelhavam como dois irmãos: fascismo e stalinismo. (FOUCAULT, 1990, p. 44-45).

Foucault coloca-nos diante de um problema ligado à nossa racionalidade historiadora atual: se a relação tempo/espaço se encontra fragmentada e toda forma de conceber uma temporalidade de base para a história só pode ser realizada justamente a partir da superposição de tempos diferentes, corremos o risco de fazer uma análise da relação passado/presente/futuro conforme certas promessas de emancipação futura. Estas promessas, centradas tão somente em uma suspeita face à autoridade, podem-nos levar a uma "certeza" de visão privilegiada em relação a todos, trazendo novamente o que achamos ser apenas um problema historicamente datado: os totalitarismos, que sempre podem ser retomados em nome de uma "certeza" sobre o que é melhor para todos, conforme a pressuposta visão (Einsicht) privilegiada de uma vanguarda revolucionária. Não estaríamos vivenciando hoje apenas um problema intimamente relacionado à dimensão da atitude crítica em nossa atualidade? A crítica não coincide com a formulação de uma "certeza" privilegiada, mas é sempre a colocação de uma dúvida sobre os limites - do conhecimento, da autoridade, da ação. Como bem expressa Foucault no texto de sua conferência Qu'est-ce que la critique:

O que se busca então não é saber o que é verdadeiro ou falso, fundamentado ou não fundamentado, real ou ilusório, científico ou ideológico, legítimo ou abusivo. [...] Trata-se, assim, de evitar jogar desde o início com a perspectiva da legitimação como fazem os termos conhecimento ou dominação. [...] nunca se deve considerar que exista um saber ou um poder [...] Saber, poder, são apenas uma grade de análise [...] Não se trata, então, de descrever o que é saber e o que é poder e como um reprimiria o outro ou como o outro abusaria daquele, mas trata-se de descrever um 
nexo de saber-poder que permita entender o que constitui a aceitabilidade de um sistema, quer seja o sistema da doença mental, da delinquência, da sexualidade, etc. (FOUCAULT, 1990, p. 48-49).

Seguindo vários elementos do kantismo e reflexões feitas por Foucault, Jacques Rancière, em seu livro-entrevista cujo título é La méthode de l'égalité (O método da igualdade) (RANCIÈRE, 2012), sustenta que, para compreender sua noção de "regimes de identificação da arte”, é preciso se desvincular de uma espécie de historicismo - que vincula o que é visível e pensável à luz de noções específicas de tempo e de espaço, as quais funcionam como limitadoras da interpretação dos vestígios do passado. Como se daria esta desvinculação? Em primeiro lugar, desvinculando a noção de espaço de uma concepção completamente material-empírica, considerando-a também como "uma disposição, uma distribuição, um conjunto de relações”. Desta forma, é possível desvincular a ideia de espaço de uma submissão a duas coisas: a primeira, à noção de ideologia como "estrutura de ilusão"; a segunda, à ideia de tempo como "operador de interdição". Explicaremos melhor estas questões, com base em suas considerações em La méthode de l'égalité (2012).

Se desvincularmos a noção de espaço de uma estratificação social dada a priori, dificultamos o risco de interpretar que as pessoas não teriam capacidade para compreender algo porque são incapazes de ver o que acontece com elas. Por quê? O próprio autor afirma, em sua crítica a um conceito comum de ideologia, que há uma explicação corrente acerca dos processos de dominação: “[...] as pessoas são dominadas porque elas não compreendem as leis de dominação, e não as podem compreender porque o lugar em que se encontram faz com que elas não possam as perceber" (RANCIÈRE, 2012, p. 106).

Ao contrário desta explicação ideológica - que pressupõe um círculo de dominação que pressupõe a ignorância de grupos e indivíduos em uma situação qualquer devido ao fato de sua "incapacidade de ver" os mecanismos que as dominam - Rancière (2012) propõe que, em vez de pensar em termos de visão correta ou incorreta, pensemos em termos de lugar. Como isso se daria? 
Quando o autor faz esta proposta, certamente não está defendendo a noção já amplamente utilizada de "lugar social" - que justamente pressupõe uma "estrutura de ilusão", conforme sua posição na estratificação social vigente, para dizer se estas pessoas poderiam ou não saber o que acontece com elas. Simplesmente diz que, se elas estão em certo lugar, elas simplesmente "estão lá" - o que, em seu entendimento, ocasiona certo saber acerca do que significa "estar lá” (RANCIÈRE, 2012, p. 106). Em outros termos, não significa afirmar de antemão que os outros são ignorantes e dominados porque são pobres ou iletrados, conforme seu lugar na pirâmide social. Significa que as pessoas podem compreender exatamente o que acontece com elas e ter uma noção muito clara de sua posição em uma situação determinada, independentemente da necessidade de serem "esclarecidas" ou "orientadas" por algum intelectual ou autoridade para, a partir daí, compreenderem sua situação.

Além disso, deslocar a noção de espaço de uma ideia historicista mais tradicional implica, por sua vez, em "reprimir as questões de origem", como se a origem do pensamento, do conhecimento e da política definisse melhor uma suposta "conscientização" do estado atual das coisas. É, na visão do autor, entender que "a origem em si mesma é sempre uma espécie de cena" (RANCIERE, 2012, p. 107). A partir desta assertiva, é possível entender que, mesmo nas análises históricas mais comuns feitas na atualidade, coloca-se a "origem" de algo como critério temporal canônico indispensável para pensar o momento presente. Entretanto, o próprio resgate de uma origem é sempre feito a posteriori - combinando elementos de uma época passada na medida em que eles nos trazem critérios para pensar o presente - o que implica, em última instância, em uma prática sempre anacrônica de combinação de diferentes linhas de temporalidade em um mesmo tempo. Em seu artigo sobre o anacronismo e a verdade do historiador, publicado na revista L'inactuel em 1996, Rancière assevera que:

O conceito de anacronismo é anti-histórico porque oculta as condições mesmas de toda historicidade. Há história na medida em que os homens não se "parecem" com seu tempo, na medida em que eles agem em ruptura com "seu" tempo, 
com a linha de temporalidade que lhes põe em seu lugar e lhes impõe fazer de seu tempo tal ou qual "emprego". Mas essa ruptura não é possível senão pela possibilidade de conectar esta linha de temporalidade a outras, pela multiplicidade de linhas de temporalidade presentes em "um" tempo. (RANCIÈRE, 1996, p. 66).

Ora, se em toda interpretação histórica há a conexão de diferentes linhas de temporalidade em um mesmo tempo, o tempo não pode ser um "operador de interdição" - de modo a pressupor o impedimento de alguém em pensar ou agir de tal ou qual maneira em um momento específico, apenas por pertencer a um determinado "tempo" ou "época". Se assim fosse, chegaríamos a conclusões de difícil solução a respeito de momentos históricos de grandes conflitos. $\mathrm{O}$ autor continua sua argumentação, afirmando que:

O que me interessa a cada vez, e em particular na medida em que todas as formas de interdição, de proscrição, de prescrição passam sempre pela ideia que 'este não é ainda o tempo', 'este não é mais o tempo' ou 'nunca foi o tempo de', é que o tempo funciona sempre como o álibi do interdito. Diz-se: 'isto não é mais possível', 'isto foi a um momento, mas não é mais agora', ou 'isso só pode acontecer nesse tempo’. (RANCIÈRE, 2012, p. 108).

Desta feita, Rancière pretende, no entanto, utilizar o tempo como coexistência de linhas heterogêneas de possibilidades:

[...] deve-se passar por uma certa ideia de topografia, de disposição, de distribuição das possibilidades para eventualmente repensar o tempo como coexistência. O que o tempo classicamente nega é a coexistência. Claro que se supõe ser o espaço a forma da coexistência, mas para pensar o tempo como coexistência, deve-se, de uma certa forma, metaforizá-lo, frequentemente, de maneira espacial. (RANCIÈRE, 2012, p. 108). 
Pensar o espaço fora de uma noção clássica do tempo como delimitador de possibilidades é, de certa forma, evitar o perigo de reduzir apenas a um grupo ou ao momento presente a possibilidade de "conhecer" as grandes questões de um determinado momento passado. Talvez, os próprios grupos ou indivíduos, por mais que fossem dominados, conhecessem sua própria situação e, por sua vez, pensaram suas práticas de liberdade fora do critério de emancipação intelectual imposto por um modelo escolar bastante comum ainda em nossa atualidade: o do embrutecimento.

Neste ponto de nossa reflexão, após expor uma série de autores e ideias, podemos formular melhor uma desconcertante pergunta: até que ponto nossa crítica social e nossa racionalidade historiadora - baseada em ideias de tempo/espaço divididos em "épocas" necessárias para o grande plano da libertação humana - nos levaram ao embrutecimento e, novamente, à reprodução de uma promessa de emancipação que nos podem levar a fazer exatamente o que criticamos em nosso sistema vigente?

Uma resposta a muitas destas perguntas que fizemos ao longo desta reflexão pode estar em uma proposta, sempre mal-acabada, sempre insatisfeita, mas pelo menos, mais cuidadosa. Supor, a partir da ideia de virtude kantiana repensada por autores como Foucault e Rancière, a capacidade de juízo de todos e de qualquer um - e não apenas de um grupo supostamente privilegiado em sua "visão" - pode ser um elemento crucial para repensar os limites da atitude crítica em nosso momento conturbado. Arrogar a si o privilégio da visão e, consequentemente, imputar ao outro a culpa pela cegueira, pode sempre resultar no uso do que chamo de "último estratagema schopenhaueriano": o de deixar o objeto de discussão de lado e partir para o argumento ad personam, insultando e ultrajando nosso adversário, fazendo um "apelo à animalidade", o que leva apenas ao debate entre os iguais e ao insulto aos que discordam de nós (SCHOPENHAUER, 1997, p. 180-185). É isso o que queremos? Então, é bom nos prepararmos para a repetição de problemas muito parecidos com os do século XIX e, principalmente, os do século $\mathrm{XX}$, os quais julgamos ter ultrapassado.

Desta maneira, entendemos que, independentemente de tratarmos aqui da "década de 80 " como objeto a partir do qual 
pretendemos realizar uma investigação histórica acerca de nossas "esperanças" ou "nostalgias”, o exercício constante da crítica parece-nos, apesar de tudo, um caminho menos lesivo ao sentido comunitário do que as certezas advindas das supostas "visões privilegiadas" de nosso tão conturbado tempo.

\section{HOW IMPORTANT IS AN ERA? ANACHRONISM AND HISTORY}

Abstract: The present article seeks - from the issue raised in the academic dossier "Presence of 1980's: hopes, longings and historiography" - perform a retrospective analysis to authors such as Immanuel Kant, Georg W. F. Hegel and Karl Marx and establish the differences and similarities between these authors around the guiding thread: what is the relation that the human being has with time, space and the practice of freedom? What, then, is the importance of a 'time' for historical analysis? It can be seen that, although Hegel and Marx follow important elements of Kantian thought, both converge on a principle that differs from Kant's analysis: the notion that some groups or individuals would have a better understanding (Einsicht) of the situation of all. In this sense, we understand that the sequence between Kantian criticism and contemporary thought is mainly in the work of authors who thought the critique of the philosopher of Königsberg as 'critical attitude' before the assumption of authority. Among these authors are Michel Foucault and Jacques Rancière, who defend the eminently anachronistic feature of the work of the historian, without the presupposition of the superiority of one individual or group over the others.

Keywords: Time. Historicism. Anachronism. Michel Foucault. Jacques Rancière.

\section{Notas}

${ }^{1}$ Esta tese, levantada por Pauline Kleingeld em 1995, em seu livro Fortschritt und Vernunft: zur Geschichtsphilosophie Kants, foi devidamente investigada na tese de doutorado de Bruno Nadai, intitulada Progresso e moral na filosofia da história de Kant, publicada em 2011 pelo Programa de Pós-graduação em História da Universidade de São Paulo (NADAI, 2011). O trabalho de Nadai pode ser importante, na área acadêmica de História, para situar elementos do pensamento kantiano que permitem pensar a história no final do século XVIII e início do XIX - os quais não são devidamente aprofundados no campo específico na História, pelo menos no Brasil até o momento. 
${ }^{2}$ Esta questão é muito extensa e, certamente, ultrapassa os limites deste artigo. O objetivo aqui é apenas demonstrar que a crítica kantiana difere, em elementos substanciais, do "ser-no-mundo" heideggeriano. Para maiores informações, a leitura dos capítulos terceiro e quarto da primeira seção de Ser e Tempo, bem como a coletânea de textos de Heidegger intitulada $A$ caminho da linguagem podem ser bastante elucidativos para perceber as diferenças fundamentais entre ambos os autores (HEIDEGGER, 2013, 2015).

${ }^{3}$ Para maiores informações, ler a Primeira Introdução da Crítica da Faculdade de Julgar de Kant (KANT, 2016, p. 15-66), bem como o livro de Alfred Baeumler, Das Irrationalitätsproblem in der Ästhetik und Logik des 18. Jahrhunderts [O problema da irracionalidade na estética e na lógica do século XVIII] (BAEUMLER, 1981).

\section{Referências}

BAEUMLER, Alfred. Das Irrationalitätsproblem in der Ästhetik und Logik des 18. Jahrhunderts bis zur Kritik der Urteilskraft. Darmstadt: Wissenschaftliche Buchgesellschaft, 1981.

FOUCAULT, Michel. As palavras e as coisas. São Paulo: Martins Fontes, 1999.

. Qu'est-ce que la critique? Critique et Aufklärung. Bulletin de la Société Française de Philosophie, Paris, v. 82, n. 2, p. 35-63, avr./juin. 1990. (Compte rendu de la séance du 27 mai 1978).

HEGEL, Georg W. F. Georg Wilhelm Friedrich Hegel's Vorlesungen über die Naturphilosophie als der Encyklopädie der philosophischen Wissenschaften im Grundrisse. Berlin: Duncker und Humblot, 1847. Disponível em: <http:// books.googleusercontent.com/books/content?req=AKW5QafWlxYZUnY0PrW_8sVT8OHCmo1LSeFvv-q4QVwlWh2RinIf0aHqGBXH8mVDwMCqbuDDz-A5DD8oQAo_0f_7n8bWhGRfE5V6Y0rKvTOglcJSJ_AohWcyxiBA-cV7gdIl2qPkE7Nx1g-y4ZDPqNSg8oGgTFLr-f0HPbFsgNsfLZ3I91MID2L81fKuxpcfzmbMVIUIeHfsgd5ENKYZ6HV_tigbbADjmoUrtghCSgJ9bFghCY2IKZiMn31BOWJJgUjT-sD8MjstVNf50g8QcmaLJIW6HzV_9QzfmsnmP2M81wZagN7f2kc>. Acesso em: 3 dez. 2016.

. Georg Wilhelm Friedrich Hegel's Vorlesungen über die Philosophie der Geschichte. Berlin: Duncker und Humblot, 1848. (Werke, v. 9). Disponível em: 〈https://archive.org/details/bub_gb_oBMyeCPEDeQC>. Acesso em: 3 dez. 2016.

Anos 90, Porto Alegre, v. 24, n. 46, p. 23-44, dez. 2017 
Qual a importância de uma época? Anacronismo e história

. Princípios da Filosofia do Direito. São Paulo: Martins Fontes, 1997.

HEIDEGGER, Martin. A caminho da linguagem. Petrópolis: Vozes; Bragança Paulista: Editora Universitária São Francisco, 2015.

. Ser e Tempo. Petrópolis: Vozes; Bragança Paulista: Editora Universitária São Francisco, 2013.

KANT, Immanuel. Crítica da Faculdade de Julgar. Petrópolis: Vozes; Bragança Paulista: Editora Universitária São Francisco, 2016.

. Metafísica dos Costumes. Petrópolis: Vozes, 2013.

. Ideia de uma História Universal de um ponto de vista Cosmopolita. São Paulo: WMF Martins Fontes, 2011.

. Crítica da Razão Pura. Lisboa: Calouste Gulbenkian, 2010.

2008.

. Crítica da Faculdade do Juízo. Rio de Janeiro: Forense Universitária,

MARX, Karl. Contribuição à Crítica da Economia Política. São Paulo: Expressão Popular, 2008.

. Crítica da filosofia do direito de Hegel. São Paulo: Boitempo, 2010.

MARX, Karl; ENGELS, Friedrich. Manifest der Kommunistichen Partei. São Paulo: Meta Libri, 2008. Disponível em: <http://www.ibiblio.org/ml/libri/e/ EngelsFMarxKH_ManifestKommunistischen_s.pdf>. Acesso em: 9 nov. 2017.

. Manifesto do Partido Comunista. Porto Alegre: LP\&M, 2001.

NADAI, Bruno. Progresso e moral na filosofia da história de Kant. Tese (Doutorado em Filosofia)-Universidade de São Paulo, São Paulo, 2011.

RANCIÈRE, Jacques. La méthode de l'égalité. Montrouge: Bayard, 2012.

. Le concept d'anachronisme et la vérité de l'historien. L'inactuel, Belval (FR), n. 6, p. 53-68, 1996. Disponível em: <https://francais.cuso.ch/fileadmin/ francais/document/ranciere_anachronisme.pdf〉. Acesso em 9 nov. 2017.

SCHOPENHAUER, Arthur. Como vencer um debate sem precisar ter razão. Rio de Janeiro: Topbooks, 1997.

Recebido em: 12/06/2017

Aprovado em: 25/09/2017 